\title{
Ambientes virtuais e a pessoa com deficiência auditiva: Trabalhando o processo de ensinar e educação durante a globalização
}

\author{
Virtual environments and the person with hearing impairment: Working the process of teaching \\ and education during globalization \\ Los entornos virtuales y la persona con discapacidad auditiva: Trabajando el proceso de enseñanza \\ y educación durante la globalización
}

Recebido: 04/06/2021 | Revisado: 10/06/2021 | Aceito: 19/06/2021 | Publicado: 02/07/2021

Samuel Lopes dos Santos ORCID: https://orcid.org/0000-0003-3375-9171 Universidade Federal do Piauí, Brasil E-mail: samuellopes121314@gmail.com

Thyago de Oliveira Afonso ORCID: https://orcid.org/0000-0001-7616-9011

Universidade Federal de Pernambuco, Brasil E-mail: thyago.oafonso@gmail.com

Mariana Pereira Barbosa Silva ORCID: https://orcid.org/0000-0003-0852-8099

Universidade Estadual do Piauí, Brasil

E-mail: marianapbsilvaa@gmail.com

Eduardo de Oliveira Evangelista ORCID: https://orcid.org/0000-0002-2242-5750 Instituto Massapé, Brasil E-mail: eduaardo37@hotmail.com

Sara da Silva Siqueira Fonseca ORCID: https://orcid.org/0000-0002-2209-5501 Universidade Federal do Piauí, Brasil E-mail: ss.siqueira@hotmail.com Laísa Ribeiro Rocha ORCID: https://orcid.org/0000-0002-8147-8342 Centro Universitário UniFacid Wyden, Brasil E-mail: laisaribrocha@gmail.com

Liliane dos Santos Vieira

ORCID: https://orcid.org/0000-0003-3254-3475 Universidade Federal do Piauí, Brasil

E-mail: lilianeboaventura04@ hotmail.com

Maria Auxiliadora Lima Ferreira ORCID: https://orcid.org/0000-0002-3225-5169 Centro Universitário UniFacid Wyden, Brasil

E-mail: m_auxiliadora.lia@hotmail.com

Pedro Lucas Alves Ferreira

ORCID: https://orcid.org/0000-0002-1975-5054 Universidade Federal do Piauí, Brasil

E-mail: p.lucasnutricionista@gmail.com

Cláudia Resende Carneiro

ORCID: https://orcid.org/0000-0002-6593-5283 Universidade Federal do Piauí, Brasil E-mail: claudiacrc.resende@gmail.com

Bruna Furtado Sena de Queiroz ORCID: https://orcid.org/0000-0001-7711-926X Universidade Federal do Piauí, Brasil E-mail: brunafsqueirozenf@gmail.com Elityanne Siqueira de Sousa ORCID: https://orcid.org/0000-0002-9651-4684 Universidade Estadual do Piauí, Brasil E-mail: elityanne1983@gmail.com

Geovana Maria Rodrigues de Sousa ORCID: https://orcid.org/0000-0001-6398-8560

Centro Universitário Santo Agostinho, Brasil E-mail: geovanamaria08@hotmail.com 
Shirley Cardoso Morais

ORCID: https://orcid.org/0000-0001-8920-7945

Centro Universitário Santo Agostinho, Brasil E-mail: shirleycmorais27@gmail.com

Antônia Alikaene de Sá

ORCID: https://orcid.org/0000-0003-2479-2324 Universidade Federal do Piauí, Brasil

E-mail: allyknsa@hotmail.com

Yonara Cristiane Ribeiro

ORCID: https://orcid.org/0000-0002-6868-1629 Universidade Federal Fluminense, Brasil

E-mail: onaracristiane@id.uff.br

Lucília da Costa Silva

ORCID: https://orcid.org/0000-0001-9386-5684

Centro Universitário Santo Agostinho, Brasil

E-mail: luciliafisio@outlook.com

Dhiosen Berg da Silva Ferreira

ORCID: https://orcid.org/0000-0001-9206-309X Faculdade SENSU, Brasil

E-mail: dhiosenloirinha@hotmail.com

Flávio José Soares Valério

ORCID: https://orcid.org/0000-0003-3282-3354 Universidade Federal do Piauí, Brasil E-mail: jhosefhit@gmail.com

Mateus Lopes dos Santos

Faculdade Fatepi/Faespi, Brasil ORCID: https://orcid.org/0000-0002-9532-4563 E-mail: mls3008.santos@gmail.com

Ana Cleide Silva Nascimento

ORCID: https://orcid.org/0000-0003-2025-5644

Instituto Florence de Ensino Superior, Brasil E-mail: anacleide_silva10@hotmail.com

\title{
Resumo
}

Introdução: Historicamente as pessoas com deficiência auditiva sempre teve seus espaços de socialização restritos. As tecnologias da Informação e Comunicação vêm se constituindo em valiosas ferramentas de apoio para superar as desigualdades e contribuir para a inserção social. Objetivo: Descrever como os ambientes virtuais ajudam as pessoas com deficiência auditiva em termos de educação, socialização e globalização. Metodologia: O trabalho é um estudo exploratório, através de uma pesquisa bibliográfica. Resultados e Discussão: Constatou-se que os ambientes virtuais são de suma importância na educação formal, por melhorar a aprendizagem das pessoas com deficiência aditiva, principalmente com a utilização de vídeos. As redes sociais formam um grande ambiente capaz de disseminar e globalizar a cultura para as pessoas com deficiência auditiva. Conclusão: A utilização de ambientes virtuais são significativa importância para explorar o ensino, aprendizagem e socialização das pessoas com deficiência auditiva, no entanto, as interfaces dos sites ainda são mal planejadas, com utilização da língua oral escrita, dificultando uso desses ambientes. Desta forma, nosso artigo orienta que para um ensino mais efetivo, tais ferramentas sejam aprimoradas com foco no aprendizado e socialização das pessoas com deficiência auditiva.

Palavras-chave: Dificuldades no ensino; Ensino ao público surdo; Propostas de ensino inovadoras; Educação; Acessibilidade.

\begin{abstract}
Introduction: Historically, people with hearing impairment have always had their socialization spaces restricted. Information and Communication Technologies are becoming valuable support tools to overcome inequalities and contribute to social inclusion. Objective: Describe how virtual environments help people with hearing impairments in terms of education, socialization and globalization. Methodology: The work is an exploratory study, through a bibliographical research. Results and Discussion: It was found that virtual environments are of paramount importance in formal education, as they improve the learning of people with addictive disabilities, especially with the use of videos. Social networks form a great environment capable of disseminating and globalizing culture for people with hearing impairments. Conclusion: The use of virtual environments is significantly important to explore the teaching, learning and socialization of people with hearing impairment, however, the site interfaces are still poorly planned, with the use of written oral language, making it difficult to use these environments. Thus, our article guides that for a more effective teaching, such tools are improved with a focus on learning and socialization of people with hearing impairment.
\end{abstract}

Keywords: Teaching difficulties; Teaching to the deaf public; Innovative teaching proposals; Education; Accessibility. 


\begin{abstract}
Resumen
Introducción: Históricamente, las personas con discapacidad auditiva siempre han tenido restringidos sus espacios de socialización. Las tecnologías de la información y la comunicación se están convirtiendo en valiosas herramientas de apoyo para superar las desigualdades y contribuir a la inclusión social. Objetivo: Describir cómo los entornos virtuales ayudan a las personas con discapacidad auditiva en términos de educación, socialización y globalización. Metodología: El trabajo es un estudio exploratorio, a través de una investigación bibliográfica. Resultados y Discusión: Se encontró que los entornos virtuales son de suma importancia en la educación formal, ya que mejoran el aprendizaje de las personas con discapacidades adictivas, especialmente con el uso de videos. Las redes sociales forman un gran entorno capaz de difundir y globalizar la cultura de las personas con discapacidad auditiva. Conclusión: El uso de entornos virtuales es significativamente importante para explorar la enseñanza, el aprendizaje y la socialización de las personas con discapacidad auditiva, sin embargo, las interfaces de los sitios web aún están mal planificadas, con el uso del lenguaje oral escrito, lo que dificulta el uso de estos entornos. Así, nuestro artículo orienta que para una enseñanza más eficaz, se mejoran dichas herramientas con un enfoque en el aprendizaje y la socialización de las personas con discapacidad auditiva.
\end{abstract}

Palabras clave: Dificultades en la enseñanza; Enseñar al público sordo; Propuestas de enseñanza innovadoras; Educación; Accesibilidad.

\title{
1. Introdução
}

Historicamente as pessoas com deficiência auditiva sempre tiveram seus espaços de socialização restritos. Concomitantemente, tal fato, interfere no processo de aprendizagem e na globalização de seus conhecimentos. Isso porque a identidade surda foi construída com base em uma cultura visual e a ouvinte através de uma cultura oral. Desta forma, torna-se difícil para o surdo vivenciar, aprender e disseminar seus conhecimentos apenas através da cultura ouvinte (Da Silva; Luckma; Wilbert, 2011).

O perfil enfático e característico do indivíduo surdo, tem sido levado em consideração pela tecnologia que hoje não só facilita, mas oportuniza que surdos possam receber informações, comunicações e convites para participarem, conhecerem e aprenderem através da tecnologia virtual (Ramos, 2014). É nítido o poder de transformação proposto pela internet e, este potencial vem atualmente modificando a metodologia da vida das pessoas. Hoje a comunicação se tornou mais fácil, a emprenho nas redes sociais é crescente, a maneira de falar, se expressar, se relacionar foi modificada dentro das redes sociais. (Gomes; Góes, 2011).

O aprendizado por intermédio da tecnologia é uma proposta que busca se aproximar da realidade "justa", ora, a oferta de conteúdo didático deve buscar alcançar seu publico alvo e, hoje, dentro dos ambientes virtuais as instituições bem como os próprios aplicativos buscam inferirem conteúdos que alcance a população surda, a fim de oferecerem um perfil educativo completo e amplo (Da Silva; Luckma; Wilbert, 2011). Deixar de atender/incluir um individuo surdo, é tornar-se inferenciador de injustiças, pois dentro do mundo virtual/web o conhecimento deve ser igualitário ou a menos, buscar aproximar a realidade dos diferentes protagonistas, incluindo assim o público surdo Gomes; Góes, 2011).

As novas tecnologias da informação e comunicação, buscam tornar-se como uma importante ferramenta de apoio e de mediação na busca pela superação das desigualdades impostas pela sociedade preditora em oferta de conhecimento. É sabido que a forma de atuar dos espaços digitais/virtuais oferecem de forma direta e indireta ações capazes de alterar o modo de viver seja ele no convívio social, familiar, educativo, profissional, amoroso entre outros (Santarosa et al., 2007).

No convívio educacional, o individuo surdo se depara com uma variedade de obstáculos que vão de encontro à seus déficits funcionais e cognitivos que podem dificultar no processo de inserção e apuração as atividades pedagógicas e até mesmo com o dinamismo oferecido pelo professor/mediador durante o repasse de conhecimento, se deparando com prejuízos para o conhecimento dessa população e afastando o surdo da inclusão educacional (Medeiros; Elia; Dos Santos, 2013).

Segundo Pivetta et al (2013) a acessibilidade aos recursos da web é um componente fundamental para a inclusão na sociedade atual, esta por sua vez é entendida como, ferramenta mediadora e condicionante ao alcance e utilização de algo, busca proporcionar uso seguro e incentiva o protagonismo e a autonomia do indivíduo. Assim, a acessibilidade se torna um 
pressuposto essencial para o indivíduo surdo na busca pela inclusão aos ambientes virtuais. É fundamental que a acessibilidade esteja presente no meio físico e nos meios de comunicação e de informação, em qualquer lugar de uso público em todo território nacional (Junqueira; Martins; Lacerda, 2017). A sociedade vivencia uma corrida pela inclusão e acompanhamento nos meios digitais, contudo, os jovens são os que mais se adequam a essa realidade, pois fora de alguns contextos, essa rapidez de inovação nas formas digitais e de comunicação torna-se um problema a ser superado por aqueles que possuem alguma limitação (Ramos, 2014).

Diante desse contexto, é evidente a importância dos ambientes virtuais para a formação educacional, critica e social da comunidade surda. Dessa forma, esse trabalho tem como objetivos: mensurar como os ambientes virtuais se colocam como ferramenta de facilitação e inclusão do individuo surdo no processo educacional, social e de aprendizagem autônoma. Para tal, hipotetizou-se: há contribuições ponderantes e influenciadoras dos ambientes virtuais no processo de aprendizagem do individuo surdo. Considerando-se como problema: quais as dificuldades enfrentadas pelos indivíduos surdos no processo de aprendizagem e relacionamento dentro doas ambientes virtuais?

\section{Metodologia}

O trabalho desenvolvido seguiu os princípios do estudo exploratório, através de uma pesquisa bibliográfica, que, segundo Gil (2008), se desenvolve a partir de materiais já elaborados, como livros e artigos científicos.

Nessa perspectiva, proposta por Gil (2008), este estudo foi constituído por meio de revisão de materiais já existentes, sendo necessários para confrontar às questões futuras. Assim os artigos encontrados foram selecionados nas bases de dados da )Scientific Eletronic Library Online (SciELO) e Literatura Latino Americana e do Caribe em Ciências da Saúde (LILACS), na base de dados da SciElo foram encontrados um total de 22 artigos, sendo selecionados destes um total de 8 artigos que estavam em conformidade aos critérios estabelecidos, nas bases de dados da LILACS foram encontrados um total de 16 artigos, destes foram selecionados 4 artigos, assim a amostragem deste estudo fora composta por um total de 12 artigos.

Os critérios de inclusão para este estudo foi; artigos escritos em língua portuguesa ou inglesa, com periodicidade de publicação de 10 anos, que abordem ou contemplem os objetivos propostos por este estudo e que possuam em sua publicação resumo completo. Os critérios de exclusão foram: artigos em outras línguas as propostas pela inclusão, foram da linha objetivada pelo estudo e que apresentassem resumos sem metodologia concisa. Para a busca nas bases de dados, foram utilizados os seguintes descritores: Dificuldades no Ensino, Ensino ao público Surdo, Propostas de Ensino Inovadoras. Unindoos através do operador booleano "AND".

\section{Resultados e Discussão}

\subsection{Importância dos ambientes virtuais para pessoas com deficiência auditiva}

Até um tempo atrás os surdos se angustiavam pela carência de informações, até porque os textos escritos são muito difíceis de compreensão para alguns sujeitos surdos, pois estão em uma segunda língua para os surdos. Quando os surdos têm acesso na internet a esses vídeos, a busca de informações torna-se mais fácil e clara porque é visual, em língua de sinais, sendo a língua brasileira de sinais (LIBRAS) a mais utilizada no país. Assim, os surdos vêm incrementando seu acesso a diversos sites (Rosa; Klein, 2010).

Antigamente os surdos tinham vontade de expressar-se e de registrar suas opiniões, mas não havia como, pela falta dessas tecnologias. Eles achavam que não eram capazes de divulgar suas ideias. Com avanço tecnológico, eles são capazes de utilizar filmadoras para fazer o registro em língua de sinais de todas as suas expressões, tornando-se fácil a sua divulgação (Rosa; Klein, 2010). Hoje, apropriaram-se crítica e criativamente do espaço on-line e discutem por seus direitos, sua língua e identidade. $\mathrm{O}$ acesso à informação e possibilidade de comunicação, via internet, permitiu que esses atores sociais lutassem em 
defesa de seus próprios direitos e autonomia, democraticamente (Gomes; Santos, 2012).

$\mathrm{Na}$ sociedade atual é inegável o papel de destaque atribuído às novas tecnologias e ao uso da internet. As inovações tecnológicas são cada vez mais parte do cotidiano das pessoas, assim como vemos uma profusão de imagens, escritas, sons, entre outras semioses, que, em conjunto, circulam discursos e significados por meio das telas de televisores, computadores, celulares, outdoors e propagandas, jornais e revistas, entre outros meios (Nogueira, 2014).

O computador e a internet são recursos que fazem toda a diferença com relação à equiparação de oportunidades de acesso e compartilhamento de conhecimentos, desde que seja garantido o seu uso a todos os cidadãos (Andrioli; Vieira; Campos, 2013). A internet é torna-se uma fonte rápida e fácil de informações, no entanto, informações sem análise, interpretação e aplicação, não tem relevância social e científica. Neste sentido, a grande contribuição da internet para a educação, vai além da possibilidade de difusão de informações, ela está na capacidade de conectar sujeitos, através da criação de redes que propiciem a mudança do pensamento individual para o coletivo, desenvolvendo a autonomia, a cooperação e a capacidade de equacionar os problemas postos diariamente pela sociedade (Neves, 2009).

A responsabilidade social que envolve a inclusão de pessoas surdos em ambientes informacionais digitais deve ser vista como superação histórica, na qual estes cidadãos foram estigmatizados e deixados à margem da sociedade, quando na realidade a problemática cognitiva estava associada a um aspecto linguístico-comunicativo diferenciado e "invisível" (Corradi; Vidotti, 2013).

Os avanços tecnológicos e a internet têm motivado mudanças em diversas áreas de atuação, nas quais os equipamentos de informática e as tecnologias digitais tornaram-se um diferencial na procura por padrões de qualidade, eficiência e produtividade na moderna economia de circulação da informação (Corradi; Vidotti, 2013). Interatividade, hipertexto, mobilidade e ubiquidade são potencializadas no momento atual da internet, e os dispositivos móveis conectados possibilitam que usuários troquem, criem, divulguem e contestem informações, em qualquer lugar do mundo (Gomes; Santos, 2012).

As inúmeras mudanças que marcam a atual sociedade conectada em rede, a democratização do acesso e produção de informações em tempo real, e os softwares sociais, têm possibilitado novas múltiplas formas de participação social. Nesse cenário, mais do que meros receptores, os indivíduos interconectados coexistem no ciberespaço, compartilhando e cocriando informações, atribuindo sentidos e expressando sua autonomia (Gomes; Santos, 2012).

Segundo Scheffer, Bez e Passerino (2014), acredita-se que a imersão dos surdos no mundo midiático possa proporcionar a esses sujeitos, inscritos num grupo que se constitui em minoria, a possibilidade de maior autonomia, com as novas possibilidades de comunicação e acesso a informações, bem como a construção de sua identidade. Uma das principais contribuições das Tecnologias Digitais para as pessoas surdas é o fato de facilitar a sua comunicação com o mundo, tirando-os do isolamento em que viveram durante tanto tempo. Os dados coletados mostram o quanto o desenvolvimento tecnológico, especialmente nas últimas duas décadas, significou para os surdos (Androli; Vieira; Campos, 2013).

\subsection{Dificuldades de acesso dos surdos aos ambientes virtuais}

Pessoas surdas geralmente encontram dificuldades ao interagir com interfaces digitais que foram projetados para ouvintes. As atuais propostas de ambientes virtuais, em particular as sustentadas em Learning Managment Systems (LMSs), como o Moodle, são alicerçadas nas lógicas da língua escrita e falada, não apresentando suporte para as línguas gestuais, e exploram de forma frágil os aspectos da visualidade, tão importante para este público (Pivetta et al., 2013). O atual caráter da escrita com a informática afeta o sujeito surdo quanto a sua condição de ser levado a expressar-se em LIBRAS e em língua portuguesa. Assim, considerando que a língua portuguesa escrita para o surdo brasileiro identificado à LIBRAS é uma língua outra, o lidar com a escrita em ambientes virtuais para este sujeito demanda, além do dominar a técnica da informática, se 
relacionar com a escrita em língua portuguesa e com as possibilidades de comunicação em LIBRAS por meio de vídeos, webchats, dentre outros (De Moraes; Buscácio, 2018).

As principais barreiras encontradas, de modo geral, foram de interface mal projetada e design de informação pouco estruturado e organizado. Muitas destas não são limitadoras da interação apenas para os surdos, sendo igualmente barreiras para os usuários em geral como é o caso da funcionalidade de download de um arquivo do site, ficando o arquivo na parte inferior na barra de tarefas, o que muitas vezes não é observado (Pivetta et al., 2013).

Segundo um estudo realizado por Pivetta, Saito e Ulbricht (2014), em relação à estrutura e navegação e acesso às atividades, todos responderam que a questão do layout e organização dos conteúdos em forma de tópicos dificulta a localização de informações pela necessidade de rolagem de página. Um dos avaliadores sugeriu que o modelo de layout deveria evitar o modelo tradicional na estrutura de tópicos. Uma sugestão seria reduzir o número de itens de navegação e utilizar uma organização de conteúdos em abas, ou algum outro layout que não faça o usuário perder o contexto de visualização de menus e estrutura como acontece com o modelo de organização em tópicos.

Outra questão importante é em relação ao uso de legendas em vídeo. Não há como negar a importância deste recurso, observando a diversidade de perfis de surdos. Porém, nem sempre elas são efetivas em seu objetivo; por exemplo, uma legenda pode conter palavras que não constam do dicionário da língua de sinais, ou também ser muito rápido, visto que os surdos possuem dificuldade de ler em português. Sugere-se que todo o vídeo tenha funcionalidades de parar, avançar, retroceder e, se possível, visualização em "câmera lenta” (Pivetta et al., 2013).

\subsection{Ambientes virtuais e a educação formal dos surdos}

Há muito tempo as pesquisas na área da surdez, principalmente aquelas com enfoque na educação de surdos, discutem melhores condições de ensino e aprendizagem para esse grupo de alunos. Essas reivindicações ganharam força com a implementação de leis que garantem o uso da Língua Brasileira de Sinais - LIBRAS - no contexto escolar, mas, ainda assim, os alunos surdos encontram muitas barreiras em seu processo de educação (Nogueira, 2014).

A tecnologia é uma ferramenta de grande potencial e tem muito a oferecer na luta contra esta exclusão, mesmo assim há escassez de materiais tecnológicos voltados para ensino de LIBRAS (Schimiguel; Fernandes; França, 2014). A internet é considerada uma das Tecnologias de Informação e Comunicação - TICs disponível na atualidade e utilizada como recurso no processo educacional. Essa ferramenta tem possibilitado a elaboração de materiais didáticos interativos, tais como jogos, animações e simulações que podem auxiliar no contexto do ensino de uma segunda língua (Gediel; Soares; Oliveira, 2016).

Tais tecnologias têm sido vistas como meio de promoção de inclusão social dentro da educação. Por este interesse, a comunidade acadêmica necessita de um amplo entendimento dos estudos existentes que apresentem uma visão geral sobre o apoio à educação dos surdos através das tecnologias assistidas (Rocha et al., 2014).

No processo de ensino-aprendizagem de LIBRAS as Tecnologias de Informação e Comunicação (TICs) vêm sendo empregadas como um grande recurso de inclusão de pessoas surdas nas comunidades de aprendizagem, criando meios para surdos e ouvintes terem acesso fácil à informação e comunicação (Renoso; Tavares, 2015). A utilização das TICs viabiliza em partes o tempo e a qualidade do trabalho docente, se utilizada de forma efetiva. Isso repercute não só na elaboração das aulas, mas nos recursos tecnológicos no momento de ministrá-las, com a criação de ambientes e situações de aprendizagem para interagir melhor com os(as) acadêmicos(as) em um processo de mediação (Gediel; Soares; Oliveira, 2016).

As tecnologias ou mídias digitais têm trazido, sem dúvida, possibilidades reais de inclusão, participação e crescimento para esses discentes, e quando adotadas como ferramentas educacionais, podem qualificar muito o nível de ensino, acelerar o processo de pesquisa e ressignificar o conceito linear do saber, democratizando o processo de construção do conhecimento para esses educandos (Scheffer; Bez; Passerino, 2014). A criatividade para inovar e a busca das TICs online já existentes, 
conforme a área de conhecimento, auxiliam no processo de adoção desses materiais no cotidiano em sala de aula (Gediel; Soares; Oliveira, 2016). Segundo Rocha (2014), as principais tecnologias assistidas direcionadas ao surdo são:

- O tradutor (traduz da língua escrita para a língua de sinais);

- dicionário (banco de sinais organizados e conectados às palavras com seus respectivos significados);

- vídeo (vídeos gravados/filmados de uma pessoa realizando determinado sinal);

- escrita de sinais ou signwriting (sistema de escrita de línguas gestuais representada por símbolos);

- avatar (personagem 2/3D que representa uma pessoa que realiza os sinais).

Assim como os principais tipos de ambientes virtuais de aprendizagem existents, sendo eles: LMS - Learning Management System, CSCL - Computer Supported Collaborative Learning, M-Learning - Mobile Learning, TLearning Television Learning, MOOC - Massive Open Online Course e ITS - Intelligent Tutoring System. Sendo assim, a combinação entre ambientes virtuais de aprendizagem com alguma tecnologia assistida, pode caracterizar um ambiente educacional inclusivo, desde que o mesmo consiga atender às necessidades de seus usuários (Ramos, 2014).

A rede virtual é sem dúvida a maior fonte de informação na atualidade, substituindo o jornal impresso e as rádios, as notícias em qualquer lugar do mundo acontece em tempo real. Vários blogs, páginas pessoais, sites de informações foram desenvolvidos de forma que as pessoas possam acessar. São muitas páginas virtuais com suportes mistos de vídeo, textos e galerias fotográficas (Ramos, 2014). O computador utilizado na educação pode auxiliar no desenvolvimento de diversas competências pelo aluno surdo, como por exemplo, a aprendizagem da escrita de sinais; sua importância dá-se, pois os surdos que se comunicam por sinais precisam representar, pela escrita, a fala própria deles que é viso-espacial (Nogueira, 2014).

É preciso começar a olhar para essa participação em ambiente digital como produção que resulta no envolvimento do surdo em diferentes práticas letradas fazendo uso de diferentes linguagens e que atualmente permite outras formas de comunicação, não apenas pela escrita, mas pela sua interação com a imagem, o vídeo, a cor, o som, entre outras semioses, construindo novos significados (Nogueira, 2014).

A imagem é uma componente fundamental do processo de educação bilíngue para alunos surdos, sendo um recurso fundamental para a aprendizagem. No caso dos surdos, a imagem não é apenas ilustrativa ou decorativa; é uma linguagem alternativa, devendo ser perceptível, limpa, clara, para que o surdo consiga abstrair a ideia (Pivetta et al., 2013).

A utilização de jogos digitais no ensino de LIBRAS não só é possível como também é uma forma diferenciada, atraente e estimulante, principalmente por conta da mudança nos perfis dos alunos da atualidade, visto que vivemos na era dos "nativos digitais" (Schimiguel; Fernandes; França, 2014).

Ainda temos a utilização dos aplicativos, que segundo Santos (2016), demonstrou que estes são ferramentas que auxiliam de forma positiva o aprendizado do aluno surdo. Em poucos momentos de utilização, percebeu-se que houve um rápido retorno e um entusiasmo por parte dos alunos, principalmente. Os nativos digitais apresentam uma relação íntima com as tecnologias e isso, além de interações e elevado número de imagens, auxiliam no processo de alfabetização.

É unânime a importância dos vídeos para pessoas com surdez e, em especial, dos vídeos com língua de sinais. Os vídeos que não estão em língua de sinais devem conter legenda e dar a possibilidade de controle ao usuário para que ele possa parar, retroceder, ver o vídeo em câmera lenta e cancelar a reprodução, conforme a sua necessidade (Pivetta et al., 2013).

Segundo um estudo realizado por Pivetta, Saito e Ulbricht (2014), os avaliadores de plataformas salientaram a importância do uso da Libras junto ao conteúdo textual para melhor compreensão. Um dos avaliadores afirmou a importância da presença do vídeo em Libras junto ao seu equivalente textual para que os alunos possam realizar as comparações e aumentar sua familiaridade com a Língua Portuguesa. Ainda em relação às necessidades do surdo, atividades que explorem mais a 
visualidade, a inserção de vídeo ou outras estratégias visuais também foram enfatizadas tanto para a fixação de conteúdo, ferramentas pedagógicas, como para atividades de interação e comunicação.

Trabalhar fazendo uso de novas tecnologias, como proposta didática, pode ser considerado um contexto favorável. Porém, cabe ao docente a tarefa de explorar pedagogicamente as potencialidades que o desenvolvimento delas proporciona. Para que seja possível usufruir das contribuições das TICs é importante considerar suas potencialidades para produzir, criar mostrar, manter, atualizar, processar, ordenar (Gediel; Soares; Oliveira, 2016).

Ainda segundos esses autores, é evidente com esta experiência é que as potencialidades das TICs fascinam todos aqueles que tomam conhecimento de seu funcionamento e da eficácia de seus resultados. No entanto, a inclusão das tecnologias no processo educacional deve ser vista com responsabilidade e de acordo com o desenvolvimento que a sociedade em si opera, uma vez que essas já fazem parte do nosso cotidiano. As TICs podem dar suporte para uma melhor execução das atividades docentes, proporcionando a mediação para um ensino de qualidade, que não deve estar apoiado somente no uso das novas tecnologias na educação, mas no processo educacional como um todo (Gediel; Soares; Oliveira, 2016).

Na avaliação por usuário, segundo Pivetta, Saito e Ulbricht (2014), ficou evidente a necessidade de aliar o uso de recursos visuais aos conteúdos apresentados em português, bem como valorizar o uso da língua de sinais e suas variantes (como o SignWriting) para maior compreensão do ambiente. Além disso, os resultados indicaram também a necessidade de um ambiente claro e conciso, incluindo uma sugestão de modificação do modelo organizacional (layout). Uma proposta seria a modificação do modelo tradicional de tópicos para um modelo em abas, que torna a navegação entre os conteúdos mais visível, não exigindo a rolagem da página e evitando a consequente perda de contexto, citada pelos entrevistados.

Quanto às disciplinas que os alunos aprendem melhor, destacam-se o Português e a Ciências como as melhores disciplinas de aprendizagem, e com elas usufruem dos meios tecnológicos disponíveis na sala de aula que são o computador e a Internet. Em seguida, vem a disciplina de História, que com os DVDs e os filmes, eles conseguem aprender por meio das imagens. Todos os alunos, assim como os professores, responderam que as mídias auxiliam na comunicação entre surdos e ouvintes e ampliam o conhecimento da realidade em sua volta, expandindo os horizontes da escrita e da leitura (Scheffer; Bez; Passerino, 2014).

Ainda segundo esses autores, quanto às mídias usadas na sala de aula pelos professores com o alunado surdo, destacam-se o computador e a Internet com maior ênfase, seguidos pela câmera digital, filmadora e celular. Efetivando-se que o professor precisa organizar o trabalho (planejamento) e os alunos precisam observar e aprender como trabalhar sozinhos (buscar as informações), utilizando o computador para organizar seus trabalhos. Deste modo, as TIC e a utilização das redes sociais proporcionam uma nova relação dos atores educativos com o saber, um novo tipo de interação do professor com os alunos, uma nova forma de integração do professor na organização escolar e na comunidade profissional (Leal; Marques, 2011).

\subsection{Principais canais de interação da pessoa com deficiência auditiva nos ambientes virtuais}

Atualmente, um dos maiores desafios da sociedade da informação consiste em tornar a informação acessível a todas as pessoas, independente de sexo, raça, condição econômica, grau de instrução e limitação física ou sensorial (Da Silva; Luckma; Wilbert, 2011). A comunicação humana se dá pela linguagem, meio que permite ao indivíduo a estruturação de seus pensamentos, a verbalização dos seus sentimentos e o registro de todo conhecimento produzido (Flor; Vanzin; Ulbrich, 2013).

Ao longo da última década caminhamos tanto com o reconhecimento da LIBRAS no Brasil, como também com a evolução das tecnologias digitais, sendo que essas vêm se tornando cada vez mais multimídia e acessíveis à grande parcela da população, chegando também às pessoas com deficiência auditiva (Andrioli; Vieira; Campos, 2013). Ainda segundo esses autores, ao mesmo tempo em que a LIBRAS era reconhecida e disseminada, as tecnologias, à medida que evoluíam, já 
contribuíam para que os surdos pudessem se comunicar, dentro e fora de sua comunidade, e, ainda, com os ouvintes (não surdos), como foi destacado pelos entrevistados para esta pesquisa.

Seguindo a dinâmica complexa da estrutura da sociedade em rede, novas práticas sociais tomam forma, potencializadas pelas tecnologias da informação e comunicação (Gomes; Santos; 2012). As novas tecnologias favorecem, para além da informação, um espaço de discussão e debate sobre diferentes temáticas de forma a ocupar os jovens com atividades como bate-papo com os amigos, encontros virtuais, sites de relacionamento, participando em chats educativos (Ramos, 2014). Ocupando um papel fundamental na vida cotidiana, a internet mudou a forma como vemos e apreendemos o mundo. Compramos e vendemos pela rede, enviamos e recebemos e-mails, contatamos clientes e amigos, acessamos e produzimos informações, tudo isso quase instantaneamente (Gomes; Santos, 2012). Com tantas redes sociais e a mídia eletrônica, cada vez mais jovens estão participando e interagindo com outros por meio destas tecnologias.

No cenário contemporâneo da globalização é importante verificar a interação dos surdos e as redes sociais. Os softwares sociais constituem-se uma das principais características da WEB 2.0. Essas interfaces digitais em rede viabilizam e estruturam a interconexão entre sujeitos, dispersos ou não, geograficamente. Possibilitando que indivíduos interajam colaborativamente, compartilhando suas autorias, favorecendo a autonomia e a socialização, criando ou estreitando vínculos sociais e afetivos, implicando em novas formas de ver e apreender o mundo. Exemplo disso são as diversas manifestações políticas fomentadas e organizadas vias softwares sociais (Gomes; Santos, 2012). Ademais, como Leal e Marques (2011), destacam:

\begin{abstract}
"As Redes Sociais possibilitam diversos tipos de relações - de trabalho, de estudo, de amizade, entre outras, apesar de quase sempre passarem despercebidas. As redes sociais ultrapassaram o âmbito académico e científico e vêm conquistando e ganhando espaço noutras esferas. Podemos observar esse movimento que conquista cada vez mais adeptos, aglutinando pessoas com interesses em conteúdo específicos, ou interesses em estabelecer relacionamentos. Tudo isto é suportado com um "software social" que, com uma interface amigável, apoia os conteúdos e interação. O uso desses recursos gera uma rede em que os membros convidam os seus amigos, conhecidos, sócios, clientes, fornecedores e outras pessoas dos seus contatos para participar na sua rede, desenvolvendo uma rede de contatos profissional e/ou pessoal, que certamente irá ter pontos de contato com outras redes."
\end{abstract}

Para Ramos (2014), o Facebook é uma rede social que num momento globalizado diminui a distância entre as pessoas e torna todos iguais em acesso, não há barreiras, falta de informação, tudo está ali à disposição, todos postam, todos leem, não há limites para a expressividade, especialmente dos surdos. Ainda segundo Ramos (2014), os surdos que acessam o Facebook buscam interagir com outros surdos e o espaço virtual possui muitas informações e ferramentas de escrita, postagens de imagens e vídeos como um jornal visual para surdos. Tudo acontece em tempo real, as postagens acontecem para todos e a cada momento novas outras postagens são incluídas.

As Redes Sociais on-line constituem relações e estabelecem ligações entre os membros de um grupo buscando conectar pessoas e proporcionar sua comunicação. A interação de uma comunidade promove a partilha da informação e do conhecimento incentivando o desenvolvimento de inovações, uma vez que os membros de uma comunidade buscam por objetivos comuns na grande maioria das vezes (Leal; Marques, 2011).

O Facebook, além de um espaço de interação entre os surdos, também é utilizado para manifestações e luta das pessoas com deficiência auditiva. Os surdos utilizam esse espaço para criar diversos grupos e comunidades sobre surdez, por exemplo, foi criado um grupo aberto, para divulgação e troca de informações entre os surdos. O nome do grupo: "Ines - Escola dos surdos, fechamento ou inclusão, seja o que for, NÃO!!!” Expressando a vontade dos surdos de continuarem estudando em um colégio de surdos (Gomes; Santos, 2012). Ainda segundo esses autores, no dia 24 de março de 2011, um surdo, muito conhecido por sua atuação em defesa das pessoas com deficiência auditiva, disponibilizou no Youtube e divulgou via Facebook, um vídeo, em LIBRAS, onde declarava sua total indignação com a notícia do fechamento do instituto. Com mais de 


\subsection{0 acessos registrados.}

Outro exemplo citado por Gomes e Santos (2012) foi o da manifestação, organizada pela Federação Nacional de Educação e Integração de Surdos (FENEIS), que ocorreu no dia 20 de maio de 2011 e contou com mais de 4.000 pessoas em frente à Explanada dos Ministérios. Antes do evento, o Youtube e Facebook foram inundados com imagens e vídeos em apoio à causa, além de muitos convites para a passeata, inclusive um vídeo explicativo48 sobre regras, direitos e deveres do manifestante.

Qualquer pessoa pode, atualmente, localizar esses materiais utilizando palavras-chave no maior portal de vídeos que temos hoje, o YouTube. Vale ressaltar que esse portal foi criado em 2005, nos Estados Unidos, e é possível localizar nele inúmeros vídeos produzidos por pessoas surdas, com diferentes finalidades. Nota-se que há vídeos com legenda ou tradução para língua oral, feitos para a comunidade ouvinte, porém, com informações consideradas relevantes pelos surdos, e outros vídeos, feitos totalmente em Língua de Sinais, reduzindo o acesso da comunidade majoritária que não compreende LIBRAS. Nesse último caso os vídeos abordam demandas específicas para organização da comunidade (Andrioli; Vieira; Campos, 2013).

\section{Conclusão}

Dentro do âmbito escolar, os ambientes virtuais são de suma importância para melhorar a aprendizagem dos surdos, principalmente com a utilização de vídeos. Neste caso, é importante salientar que os professores devem ter o máximo de atenção ao preparar os materiais didáticos para que os alunos surdos possam assimilar os conhecimentos propostos.

As redes sociais formam um grande ambiente capaz de disseminar e globalizar a cultura das pessoas com deficiência auditiva. É a partir delas que os surdos conseguem se socializar, compartilhar seus conhecimentos, desejos, emoções e reivindicarem seus direitos. Essa socialização e globalização da cultura surda, faz com que essa população se sinta mais participativa e menos excluída da sociedade.

Apesar dos ambientes virtuais já serem bastantes utilizados pela comunidade surda, ainda existem muitas dificuldades por parte dos surdos em utilizá-los. Portanto, esse estudo é de suma importância por apresentar como os ambientes virtuais podem auxiliar os surdos em termos de educação, socialização e globalização de sua cultura. Além disso, ressaltamos que os ambientes virtuais necessitam de adequações estruturais de acessibilidade para que as principais dificuldades de utilização desses ambientes pelos surdos sejam sanadas.

\section{Referências}

Andrioli, M. G. P., Vieira, C. R., \& Campos, S. R. (2013). Uso das tecnologias digitais pelas pessoas surdas como um meio de ampliação da cidadania. VII Encontro da Associação Brasileira de Pesquisadores em Educação Especial.

Corradi, J. A. M., \& Vidotti, S. A. B. G. (2013). Ambientes informacionais digitais acessíveis a minorias lingüísticas surdas: cidadania e/ou responsabilidade social.

Da Silva, R. A., Lückman, A. P., \& Wilbert, J. W. (2011). Acessibilidade de AVAs para o usuário PNEE: uma visão introdutória Accessibility of AVAs for handicapped users of PNEE: an introductory view. Revista ACB, 16(1), 217-233.

De Morais, F. B. C., \& Buscácio, L. L. B. (2018). Leitura, Escrita E Tecnologia Para Aprendizes Surdos. Linha Mestra, (36), 30-36.

Flor, C. D. S., Vanzin, T., \& Ulbricht, V. (2013). Recomendações da WCAG 2.0 (2008) e a acessibilidade de surdos em conteúdos da web. Revista Brasileira de Educação Especial, 19(2), 161-168.

Gediel, A. L. B., Soares, C. P., \& Oliveira, C. L. R. D. (2016). O ambiente virtual como aliado no processo de ensino e aprendizagem da Libras.

Gil, A. C. (2008). Métodos e técnicas de pesquisa social. (6a ed.), Ediitora Atlas SA.

Gomes, R.C.; \& Góes, A. R. (2011). E-acessibilidade para surdos. Revista Brasileira de Tradução Visual, 7.

Gomes, R. C., \& Santos, E. (2012). Ciberativismo Surdo: em defesa da educação bilíngue. Revista Teias, $13(30), 24$. 
Research, Society and Development, v. 10, n. 7, e54910716808, 2021

(CC BY 4.0) | ISSN 2525-3409 | DOI: http://dx.doi.org/10.33448/rsd-v10i7.16808

Junqueira, R. D., Martins, D. A., \& Lacerda, C. B. F. (2017). Política de acessibilidade e exame nacional do ensino médio (ENEM). Educação \& Sociedade, 38(139), 453-471.

Leal, J. (2011). Redes Sociais na sala de aula. Indagatio Didactica, 3(2), 129-143.

Medeiros, L. P., Elia, M., \& dos Santos, M. P. (2013). Estratégias para auxiliar o Processo de Aprendizagem da Leitura e Escrita de Alunos Surdos. In Anais do Workshop de Informática na Escola. 1, 340).

Nogueira, A. S. (2014). Práticas de letramento multimodais em ambiente digital: uma possibilidade para repensar a educação de surdos. Intercâmbio. Revista do Programa de Estudos Pós-Graduados em Linguística Aplicada e Estudos da Linguagem.

Neves, G. V. (2009). Ensino de História para alunos surdos de ensino médio: desafios e possibilidades. In Congresso Nacional de Educação. 9, $7903-7912$.

Pivetta, E. M., Saito, D. S., Almeida, A. M. P., \& Ulbricht, V. R. (2013). Contribuições para o design de interface de um Ambiente Virtual de Ensino Aprendizagem acessível a surdos. InfoDesign-Revista Brasileira de Design da Informação, 10(2), 193-206.

Pivetta, E. M., Saito, D. S., \& Ulbricht, V. R. (2014). Surdos e acessibilidade: análise de um ambiente virtual de ensino e aprendizagem. Revista Brasileira de educação especial, 20(1), 147-162.

Ramos, F. M. (2014). A comunidade surda e o facebook. Revista Ampliar, 1(1).

Reinoso, L., \& Tavares, O. (2015, October). MVLIBRAS: ambiente digital para comunidades de aprendizagem com recursos inclusivos para surdos. In Brazilian Symposium on Computers in Education (Simpósio Brasileiro de Informática na Educação-SBIE). 26, 772.

Rocha, D. F., Bittencourt, I. I., Dermeval, D., \& Isotani, S. (2014). Uma revisão sistemática sobre a educação do surdo em ambientes virtuais educacionais. In Brazilian Symposium on Computers in Education (Simpósio Brasileiro de Informática na Educação-SBIE). 25, 1263.

Rosa, F. S; Klein, M. (2010). Literatura Surda: marcas surdas compartilhadas. CIC.

Santarosa, L. M. C., Passerino, L. M., Basso, L. D. O., \& Dias, C. D. O. (2007). Acessibilidade em Ambientes de Aprendizagem por Projetos: construção de espaços virtuais para inclusão digital e social de PNEEs. RENOTE: revista novas tecnologias na educação.

Santos, B. (2017). A utilização de aplicativos na alfabetização de surdos. Instituto Federal de Educação, Ciência e Tecnologia Fluminense, http://bd. centro. iff. edu. br/bitstream/123456789/1115/1/A\% 20utiliza\% C3\% A7\% C3\% A3o\% 20de\% 20aplicativos\% 20na\% 20alfabetiza\% C3\% A7\% C3\% A3o\% 20de\% 20surdos. pdf>.

Scheffer, M. L. C., Bez, M. R., \& Passerino, L. M. (2014). Mídias digitais na educação de surdos. Objetos de aprendizagem: teoria e prática. Evangraf, 310330 .

Schimiguel, J., Fernandes, R. F., \& dos Santos França, L. (2014). Desenvolvimento de objetos de aprendizagem na forma de jogos para ensino de libras. Sintec-IV Simpósio Nacional de Ensino de Ciência e Tecnologia. 